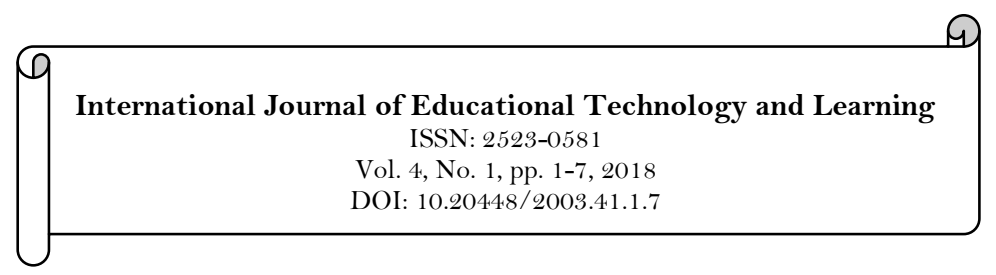

$\gamma_{\text {updates }}^{\text {check for }}$

\title{
Strategies Used to Enhance Parent Involvement on Performance of Early Childhood Education in Kisii, Nyamira and Homabay Counties, Kenya
}

\section{Ogoti Evans Okendo ${ }^{1}$}

${ }^{1}$ Head Department of Education Curriculum and Instruction Mwenge Catholic University, Moshi, Tanzania. Email:eogoti17@gmail.com

\begin{tabular}{l|l} 
Abstract & \\
The study sought to establish investigate the strategies that enhance & Keywords: \\
parent involvement on performance of Early Childhood Education in & Communication strategy \\
Kisii, Nyamira and Homabay counties. The study was based on & Collaboration strategy \\
Epstein's theory of overlapping spheres of influence. This study & Volunteering strategy. \\
employed a convergent parallel design. Data was collected from 223 & \\
respondents who included parents, head teachers, ECD teachers and & \\
programme officers from the three counties. The respondents were & Licensed: \\
sampled using probability and non- probability sampling procedures. & This work is licensed under a \\
Questionnaires, interview guide and observation schedules were used & 4.o License. \\
to collect primary data. A pilot test was conducted in five schools in & \\
Kisii South Sub-County to assess validity of the research instruments & Publisher: \\
whereas split half method used to ascertain the reliability of & Scientific Publishing Institute \\
questionnaire, dependability and credibility determined the reliability \\
of interview guide. Quantitative data was analyzed using both
\end{tabular}

\section{Introduction}

The impact of parent involvement in a child's growth and development is generally accepted. However, educators, parent groups, and policy makers continue to debate the issue of whether or not parent involvement has a beneficial effect on the academic achievement of children.

A key element in these debates is how parent involvement is defined. Therefore, it is important to understand how parent involvement is defined before conclusions are drawn on the impact of parent involvement. In addition, it is important to understand what aspects of parent involvement have the greatest impact and whether the impact is consistent across children characteristics such as socioeconomic status, race, and the child's grade level, age, and gender.

During the past several decades, there have been numerous primary studies investigating various aspects of parent involvement and the effect it has on children's learning. The No Child Left behind Act (NCLB) has served to focus attention on the need and importance of parent involvement intheir child's education.

In 2006, the Kenya government adopted a policy on Early Childhood Development (ECD). The policy document outlines a comprehensive framework that encompasses policies for early childhood services and programs for children from conception to age eight years. 
Also, it outlines an ECD policy system and provides a frame of reference in the provision of services for infants and children. Further, it provides a basis to strengthen, develop, and review policies related to health and nutrition, education, water and sanitation, and social services. According to a 2006 policy document, the Republic of Kenya sector policies are central in providing standards and guidelines for ensuring provision of quality services for all children in their earliest years.

The development of this policy document was necessary because the existing sectoral guidelines relating to services for infants and children were not supported by a clear overarching early childhood policy framework. Without the comprehensive policy framework, the provision of these services and programs had tended to take a segmented approach within fragmented sectoral initiatives.

Numerous service providers in programs for infants and children had been developed and implemented initiatives and interventions without sufficient collaboration and coordination. This resulted in duplication of resources and services, gaps in service delivery and at times even unhealthy competition adversely affecting the provision of quality services for holistic development of the child.

The first six years of life are most important for the development of human kind during which time children experience exceptionally fast growth and development in all aspects with brain growth being the most rapid.

The pre-school years further present crucial opportunities for the development of parents 'involvement in their children's early education. Active involvement of parents' in their children's learning has been shown to improve their academic outcomes (Arnold, Zeljo, Doctoroff, \& Ortiz, 2008; Powell, Son, File, \& San, 2010). The preschool years represent crucial opportunities for the development of parental involvement in children's early education (Arnold et al., 2008), as parents' active involvement in their children's learning has been shown to improve children's academic, behavioral, and social outcomes (Marcon, 1999; Powell et al., 2010; Senechal, 2006).

In particular, Parent Involvement facilitates children's development of pre-literacy skills such as phonological awareness and letter name knowledge (Powell et al., 2010). These skills have been shown to be essential for later school success. Moreover, the transition to preschool marks the beginning of an important relationship between home and school (Powell et al., 2010).

A child's first experiences in school are often parents' first experiences as critical stakeholders in their child's formal schooling. Parent Involvement during preschool may also allow parents to develop skills in working collaboratively with school personnel. Parent Involvement may be particularly important for children from low-income families. The preschool years are therefore an optimal time to establish Parent Involvement and to familiarize parents of children at-risk for academic difficulties with the skills children need to acquire prior to entering elementary school.

After independence in 1963 Kenya made significant gains in the health and nutrition status of young children. Infant and child mortality, morbidity and immunization rates all improved, particularly up to the mid-1990s. For example, in 1962 the under-five mortality rate was 211 per 1000 live births. This declined significantly in the following years, reaching 150 per 1000 live births in 1979 and 105 per 1000 live births in 1989. Unfortunately from the mid-1990s these gains appear to have been lost: since then there has been an increase in the under-five mortality rate back up to 115 deaths per 1000 live births in 2003. Infant mortality in 2003 stood at 77 deaths per 1000 live births.

This means that one in every nine children dies before his or her fifth birthday, and in some districts the rate is one in five children. In addition, research evidence documents that parents and other caregivers are not stimulating and caring for their young children as they used to do in traditional societies. The decline in quality parental care may be one of the factors contributing to rising under-five mortality rates, as well as growing concerns about the healthy psychosocial development of children.

The World Conference on Education for All (EFA) that took place in Jomtien, Thailand, in March 1990, articulated the significance of the early years as the foundation for the life of an individual.

These deliberations have been corroborated by recent research on brain development which emphasizes that the first six years of life are extremely important because :( a) the environmental experiences during this period are significant in influencing one's life. The experiences of this period are known to either enhance or inhibit realization of one's potential in life. (b) This is also the fastest period of growth and development in all aspects. (c) The development of the brain is most rapid in the early years. By the second year of life the brain of the child is $70 \%$ of an adult brain. By six years of age it reaches $90 \%$ of its adult weight and size. In addition, by the end of six years the brain of the child has developed maximum connections, more than an individual will require in a lifetime.

All that is left is to make these connections permanent through providing early stimulation and quality care. (d) All the "critical windows of opportunity" are open during this period. These are the periods when children are able to learn and acquire certain knowledge, skills and attitudes very quickly with minimal effort. Parents, other caregivers and teachers need to make use of this period in order to maximize children's holistic development and, therefore, their potential in life. (e) This is the period when the brain is most malleable and also highly impressionable. Environmental influences, especially care, nurture and stimulation, have the greatest impact on the brain. (f) This is the period when it is very easy to mould the character of children by 
inculcating social norms, values and habits as well as regulation and control of emotions. (g) This is a vital period for ensuring proper physiological growth and a crucial period for significant health and nutrition interventions to put the child on the right track for life.

In sub-Saharan African countries, there are many differences in parent's participation in the school system their children attend across the continent. Some invest their time and money in their children's school, and still others have no input at all because schools especially in rural set up do not create opportunities for them to participate as many of the parents have very few years of formal education besides being occupied with domestic chores.

There are numerous stakeholders involved in provision of services for infants and children, yet the resources available are too few for the number of children requiring the services. There is, therefore, a need to optimize the use of available resources, and thus ensure that the services are equitably accessible, affordable and culturally relevant. This will also ensure more effective coordination of service delivery among the partners.

As the Government and other stakeholders strive to accomplish the goals of increasing access to services, enhancing quality of services and ensuring services are equitably distributed, challenges will arise that need to be addressed through the development of specific strategies. In most cases it will not be possible to address all of the challenges at once.

There will be need to prioritize them so that those that are most critical are addressed first. For young children, this suggests that the challenges that directly impact upon the holistic development of children and families will be given priority

\subsection{Statement of the Problem}

The government of Kenya implemented a partnership policy that aimed to promote the relationship between parents, teachers and the community in enhancing children education. This partnership will be possible if there are well developed programs in Early Childhood Education in all the counties.

Review studies such as Kimu (2012) and Koech (2013) found out that parent involvement in pre-schools and primary schools was still low. Although the reviewed studies have dealt in parental involvement in preschools and primary schools, the cultural background in the three situations might result to differences in methods of parent involvement thus necessitating in performance of Early Childhood Education in preschools. Since then what strategies have pre-schools adopted to increase parent involvement in children education? The study there sought to investigate Strategies used to enhance parent involvement on performance of Early Childhood Education among rural households in Kisii, Nyamira and Homa bay Counties, Kenya.

\subsection{Research Questions}

1. What are the strategies of parent involvement adopted to enhance performance in Early Childhood Education in Kisii, Nyamira and Homa bay counties?

2. What parental involvement strategies are more preferred in enhancing performance in Early Childhood Education in Kisii, Nyamira and Homa bay counties?

\subsection{Hypothesis}

There is no significant relationship between strategies of parental involvement applied and pupil's performance in Early Childhood Education in Kisii, Nyamira and Homa bay counties

\subsection{Theoretical Framework}

This study was guided by the theory of overlapping spheres of influence by Epstein (1987). The concept of overlapping spheres of influence is based on the need for social organization that posits that the most effective families and schools have overlapping, shared goals and mission concerning children and conducts some work collaboration. It developed a framework of five major types of involvement which include style of parenting, level of communication from school and to school, volunteering, learning activities at home and decision making. A sixth type of school and family partnership was later added: collaborating with the community bringing forth Epstein's typology of parent involvement.

The six types of involvement can guide the development of a balanced comprehensive programme of partnership including opportunities for family involvement at school at home, with potentially important results for learners, parents and educators. Epstein's typology is widely considered to capture the essence of home-based-community relations. In Australia and America, these six types of involvement by Epstein have been found to work well and considered a comprehensive program (Christenson, Rounds, \& Franklin, 1992). In the Kenyan context, specifically this study, the specific types of involvement from Epstein's typology were established although the biggest barrier to such involvement is where schools do not have a programme or strategy to involve parents (Epstein, 1987). 


\section{Research Design and Methodology}

The study adopted mixed research method approach. Utilizing the convergent parallel design the purpose of a convergent of Parallel mixed methods design was to simultaneously collect both qualitative and quantitative data, merge the data and use the results to understand a research problem.

Mixed method approach not only allows the researchers to be more confident in the results of the study but also provides a clearer understanding of the phenomenon of the study (Jick, 1979). More specifically, by combining the quantitative and qualitative approaches, this study sought to not only bring out the major trends (patterns) and practices in faculty performance but also to elicit specific voices from lecturers and academic managers. Utilizing mixed methods is not without limitations. For instance, it makes replication exceedingly difficult (Jick, 1979).

Data for this study was collected from 160 parents, 36 ECD teachers, 24 head teachers and 3 prograsmme officers making a total of 223 respondents. The selection of parents was conducted through probability sampling procedures that is simple random sampling and stratified random sampling to select 40 from each of the three sampled districts.

The ECD teachers and programme officers were selected through purposive sampling procedures as key informants. To supplement data collected from the primary respondents document analysis guide was used to collect secondary data from ECD centres. Pilot test was conducted in five schools in Kisii South Sub County.

Data analysis occurred in two stages.

The first stage involved the processing quantitative data from the questionnaire administered to the primary respondents of the study. During this stage, descriptive statistics especially frequency distributions, percentages and, where applicable, means were computed and utilized to display data patterns; that is, to construct a descriptive profile of the study sample and to depict the patterns on strategies targeted by the study. Split half technique used to ascertain the reliability of questionnaire, dependability and credibility determined the reliability of interview guide.

\section{Research Findings and Discussions}

3.1. Strategies of Parent Involvement Adopted to Enhance Performance in Early Childhood Education

The study sought to find out the strategies of parent involvement adopted to enhance performance in Early Childhood Education in rural households. The responses were summarized and presented in Table 1, 2, and 3.

Table-1. Parents responses on strategies of parent involvement $(\mathrm{N}=160)$.

\begin{tabular}{|c|c|c|c|c|c|c|}
\hline Strategies; & SD (\%) & D (\%) & $\mathrm{U}(\%)$ & $A(\%)$ & SA (\%) & Mean(SD) \\
\hline $\begin{array}{l}\text { I always help my child in } \\
\text { homework after school and when } \\
\text { schools are closed }\end{array}$ & $10(6.2)$ & $6(3.7)$ & $3(1.9)$ & $62(38.5)$ & $80(49.7)$ & $4.22(1.088)$ \\
\hline $\begin{array}{l}\text { When called by the teacher, I } \\
\text { make sure I respond to the call }\end{array}$ & $5(3.1)$ & $\mathrm{O}(0.0)$ & $\mathrm{O}(0.0)$ & $50(31.7)$ & $105(65.2)$ & $4.56(0.789)$ \\
\hline $\begin{array}{l}\text { I follow my child's progress by } \\
\text { consulting the teacher and } \\
\text { checking the report books }\end{array}$ & $5(3.1)$ & $3(1.9)$ & $1(0.6)$ & $50(31.7)$ & $103(63.4)$ & $4.5(0.867)$ \\
\hline $\begin{array}{l}\text { Always attend parent meetings in } \\
\text { school }\end{array}$ & $5(3.1)$ & $3(1.9)$ & $3(1.9)$ & $60(36.6)$ & $91(56.5)$ & $4.42(0.61)$ \\
\hline $\begin{array}{l}\text { I like discussing my child's } \\
\text { strengths and weaknesses with } \\
\text { the teacher }\end{array}$ & $5(3.1)$ & $4(2.5)$ & $12(7.5)$ & $53(32.3)$ & $88(54.7)$ & $4.33(0.947)$ \\
\hline $\begin{array}{l}\text { I read with the child at home } \\
\text { when free }\end{array}$ & $7(4.3)$ & $5(3.1)$ & $12(6.8)$ & $55(34.2)$ & $83(51.6)$ & $4.25(1.14)$ \\
\hline
\end{tabular}

Data in Table 1 indicates that majority of the parents help their children in homework, follow their children progress by consulting teachers, attend parent meetings, discuss their children strengths and weakness and read with their children at home when free. This was confirmed further by each item having a mean of 4 and above. 
Table-2. ECD Teachers and head teachers' responses on strategies of parent involvement (N=60).

\begin{tabular}{l|l|l|l|l|l|l}
\hline Strategies; & SD (\%) & $\mathbf{D}(\%)$ & $\mathbf{U}(\%)$ & $\mathbf{A}(\%)$ & SA (\%) & Mean(SD) \\
\hline $\begin{array}{l}\text { Parents help their children to do } \\
\text { homework after school and when } \\
\text { schools are closed }\end{array}$ & $1(1.4)$ & $17(24.3)$ & $6(8.6)$ & $25(35.7)$ & $21(30.0)$ & $3.69(1.186)$ \\
\hline $\begin{array}{l}\text { Parents come to school } \\
\text { whenever they are called }\end{array}$ & $0(0.0)$ & $6(8.6)$ & $7(10.0)$ & $44(62.9)$ & $13(18.6)$ & $3.91(0.794)$ \\
\hline $\begin{array}{l}\text { Parents follow-up their } \\
\text { children's progress by consulting } \\
\text { the teacher and checking the } \\
\text { report books }\end{array}$ & $3(4.3)$ & $13(18.6)$ & $8(11.4)$ & $42(60.0)$ & $4(5.7)$ & $3.44(1.002$ \\
\hline $\begin{array}{l}\text { Parents always attend meetings } \\
\text { in school }\end{array}$ & $1(1.4)$ & $14(20.0)$ & $4(5.7)$ & $40(57.1)$ & $11(15.7)$ & $3.66(1.02)$ \\
\hline $\begin{array}{l}\text { Parents discuss their children's } \\
\text { strengths and weaknesses with } \\
\text { the teacher }\end{array}$ & $14(20.0)$ & $4(5.7)$ & $14(20.0)$ & $24(34.3)$ & $14(20.0)$ & $3.29(1.395)$ \\
\hline $\begin{array}{l}\text { We call parents to discuss their } \\
\text { children's progress and discipline }\end{array}$ & $18(25.7)$ & $4(5.7)$ & $3(4.3)$ & $27(38.6)$ & $18(25.7)$ & $3.33(1.558)$ \\
$\begin{array}{l}\text { Data in Table indicates that majority of the parents help their children to homework, follow up their children progress, attend school meetings, discuss the } \\
\text { strengths and weaknesses of their children and participate in discipline matters affecting their children in school. This was further supported with a mean of } 3 \\
\text { and above. }\end{array}$ & & &
\end{tabular}

Table-3. Parent's responses on strategies $(\mathrm{N}=160)$.

\begin{tabular}{|c|c|c|}
\hline Strategies & $\mathbf{F}$ & $\%$ \\
\hline Communication with teachers & 40 & 25 \\
\hline Involvement on student learning at home & 16 & 10 \\
\hline Collaborating with community & 56 & 35 \\
\hline Volunteering & 14 & 8.8 \\
\hline Decision making & 24 & 15 \\
\hline Parenting style & 10 & 6.2 \\
\hline
\end{tabular}

“.... There are various strategies of parent's involvement in pre-schools. Parents can make learning materials by using resources from community then bring them to be used in pre-school. They can also take part in decisions affecting their children in pre-school by choosing their representatives through elections. In addition, teachers and parents can discuss children strengths or weaknesses and this will assist the parents nurture their children's potentialities and deal with their weaknesses appropriately".

One program officer said that;

‘... Although parent involvement is very important in Early Childhood Education, there have been hitches encountered. First, in families where both parents work, parents do not attend meetings called for in preschools. This is even worse when we have majority of parents with negative attitude towards pre-school education. On the other hand the county government has not been able to provide teaching and learning resources required in most of our rural schools in the area. Also incompetence on the side of parents assisting with children's homework hinders parent involvement especially in cases where majority of parents are illiterate."

Other head teacher said;

“-----in order to improve performance of Early Childhood Education, communication between teachers and parents should be regular and opportunities for parents volunteering should be provided by pre-schools. Performance in Early Childhood Education can further be improved by parents assisting teachers improvise learning resources from the locally available materials. This will subsidize on the learning materials bought by pre-schools. Remember that children learn better by using materials from their immediate environment because they are familiar with them...."

Ho1: There is no significant relationship between strategies of parental involvement applied and pupil's performance in Early Childhood Education centres in Kisii, Nyamira and Homa bay counties 
Table-4. Correlation results.

\begin{tabular}{|c|c|c|c|c|c|c|c|}
\hline & $\begin{array}{l}\text { Pearson } \\
\text { correlation } \\
\text { Sig (2tailed) }\end{array}$ & $\begin{array}{l}\text { Performance } \\
\text { of ECD }\end{array}$ & $\begin{array}{l}\text { Parenting } \\
\text { involvement }\end{array}$ & Communication & $\begin{array}{l}\text { Learning } \\
\text { at home }\end{array}$ & $\begin{array}{l}\text { Decision } \\
\text { making }\end{array}$ & Collaborating \\
\hline $\begin{array}{l}\text { Performance of } \\
\text { ECD }\end{array}$ & & 1 & & & & & \\
\hline $\begin{array}{l}\text { Parenting } \\
\text { involvement }\end{array}$ & & $\begin{array}{l}0.0434^{* *} \\
0.001 \\
\end{array}$ & 1 & & & & \\
\hline Communication & & $\begin{array}{l}0.0466^{* *} \\
0.017\end{array}$ & $\begin{array}{l}0.536 \\
0\end{array}$ & 1 & & & \\
\hline $\begin{array}{l}\text { Learning at } \\
\text { home }\end{array}$ & & $\begin{array}{l}0.604^{* *} \\
0.002\end{array}$ & $\begin{array}{l}0.177 \\
0.143\end{array}$ & $\begin{array}{l}0.603^{* * *} \\
\mathrm{O}\end{array}$ & 1 & & \\
\hline Decision making & & $\begin{array}{l}0.371^{*} \\
0.007\end{array}$ & $\begin{array}{l}0.323^{* *} \\
0.006\end{array}$ & $\begin{array}{l}0.594^{* * *} \\
0\end{array}$ & $\begin{array}{l}0.428^{*} * \\
0\end{array}$ & 1 & \\
\hline Collaboration & & $\begin{array}{l}0.684^{*} \\
0.007\end{array}$ & $\begin{array}{l}0.193 \\
0.109\end{array}$ & $\begin{array}{l}0.430^{* * *} \\
\mathrm{o}\end{array}$ & $\begin{array}{l}0.012 \\
0.92\end{array}$ & $\begin{array}{l}0.385^{* *} \\
0.001\end{array}$ & 1 \\
\hline
\end{tabular}

Correlation is significant at the 0.05 level (2-tailed)

** Correlation is significant at the 0.01 level (2-tailed).

From the results in Table 4, the most significant relationship exists between collaboration and early childhood education with a correlation coefficient value of 0.684 (significant at $\alpha=0.05$ and P-value $=0.007$ ) which indicates that collaboration contributes up to $68.4 \%$ in performance of Early Childhood Education. Learning at home is shown to contribute a correlation coefficient value of 0.604 which is (significant at $\alpha=0.05$ and $\mathrm{P}$-value $=0.002$ ), communication is also positively correlated with a coefficient value of 0.466 (significant at $\alpha=0.05$ and $P$-value $=0.017$ ) parenting involvement has a coefficient value of 0.434 (significant at $\alpha=0.01$ and $\mathrm{P}$-value $=0.001$ ) decision making with a coefficient of 0.371 (significant at $\alpha=0.01$ and $\mathrm{P}$-value $=0.007$ ). The findings provide enough evidence to suggest that there is linear relationship between parenting involvement, communication, learning at home, decision-making and collaboration with early childhood education which implies that when the strategies mentioned are increased, performance in Early Childhood Education is also increased.

\section{Conclusions and Recommendations of the Study \\ 4.1. Conclusions}

The study established that collaboration as a strategy of parent involvement contributes significantly to performance of Early Childhood Education. This implies that teachers provide learning opportunities for children whereas parents support their development in learning

The study established that there are a number of strategies to implement so as to increase parent involvement in Early Childhood Education. For instance, teachers can engage parents in Early Childhood Education when they share children's progress. Also, regular updates on children's performance can encourage families to engage in more learning-related activities at home. Further hosting special events in school, frequent communication with parents and identifying and making useful resources available to parents and teachers are some of the strategies that can be used to enhance performance in Early Childhood Education.

The findings of the current study indicate that assigning Head Start parents an active role in developing their preschoolers' pre-literacy skills could be an effective strategy to increase home-based Parent Involvement activities. Increases in Early Childhood Education may in turn result in positive immediate and long-term academic, behavioral, and social outcomes for children. The intervention itself may also help develop preschool students' skills in letter knowledge and phonological awareness (Sundman-Wheat, 2012). Moreover, education professionals' use of the intervention would help meet the national goal of increased Parent Involvement as mandated by the No Child Left behind Act.

\subsection{Recommendations of the Study}

There is need for parents to track their child's academic progress by consulting with the teacher and checking the report books regularly.

There is need for parents to be involved in discussions with their children about education and their interests. In order to improve parent involvement in Early Childhood Education there is need to encourage parents to engage in more learning related activities at home.

There is need for schools to improve communication between parents and teachers to play a key role in enhancing parent involvement. For instance, communication through parent-teacher meetings or through printed materials. 


\section{References}

Arnold, D. H., Zeljo, A., Doctoroff, G. L., \& Ortiz, C. (2008). Parent involvement in pre-school: Predictors and the relations of involvement to pre-literacy development. School Psychology Revierw, 37(1), 74-90.

Christenson, S. L., Rounds, T., \& Franklin, M. J. (1992). Home-school collaboration effects, issues and opportunities. Illionois. School Psychology Quarterly, 4, 19-51.

Epstein, J. L. (1987). Parent involvement: State education agencies should lead the way. Community Education Journal, 14(2), 4-10.

Jick, T. D. (1979). Mixing qualitative and quantitative methods: Triangulation in action. Administrative Science Quarterly, 24(1), 602-611.

Kimu, A. M. (2012). Parent involvement in public primary schools in Kenya. PhD Dissertation: University of South Africa.

Koech, K. P. (2013). Parent-teacher partnerships for enhancing pre-school Children's Education in UAasin Gishu District, Kenya.

Marcon, R. A. (1999). Positive relationships between parent school involvement and public school inner city preschoolers' development and academic performance. School Psychology Review, 28(3), 395-412.

Powell, D. R., Son, S., File, N., \& San, J. R. R. (2010). Parent-school relationships and children's academic and social outcomes in public school pre-kindergarten. Journal of School Psychology, 48(4), 269-292.

Senechal, M. (2006). The effect of family literacy interventions on children's acquisition of reading. From kindergarten to grade 3. A meta-analytic review. Washington DC National Institute for Literacy.

Sundman-Wheat, A. (2012). A head start to learning: Exploration of a parent-directed intervention to promote early literacy skill development. (Unpublished Doctoral Dissertation). University of South Florida, Tampa. 